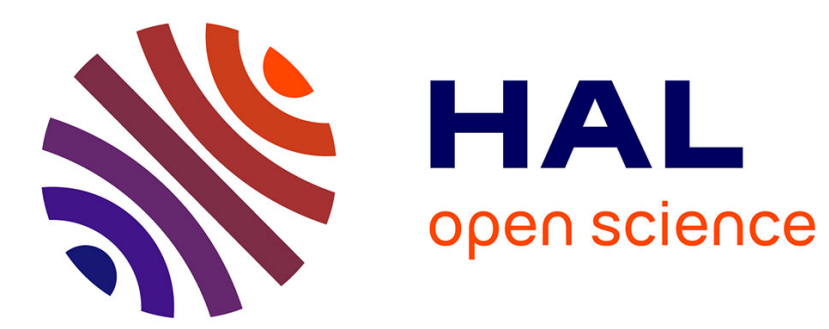

\title{
Neurolinguistic aspects of attrition
}

Barbara Köpke

\section{To cite this version:}

Barbara Köpke. Neurolinguistic aspects of attrition. Journal of Neurolinguistics, 2004, 17 (1), pp.3-30. 10.1016/S0911-6044(03)00051-4 . hal-00856482

\section{HAL Id: hal-00856482 \\ https://hal.science/hal-00856482}

Submitted on 9 Sep 2013

HAL is a multi-disciplinary open access archive for the deposit and dissemination of scientific research documents, whether they are published or not. The documents may come from teaching and research institutions in France or abroad, or from public or private research centers.
L'archive ouverte pluridisciplinaire $\mathbf{H A L}$, est destinée au dépôt et à la diffusion de documents scientifiques de niveau recherche, publiés ou non, émanant des établissements d'enseignement et de recherche français ou étrangers, des laboratoires publics ou privés. 


\title{
Neurolinguistic aspects of attrition
}

\author{
Barbara Köpke \\ Laboratoire Jacques Lordat (EA 1941) \\ Institut des Sciences du Cerveau de Toulouse (IFR nº 96) \\ Université Toulouse-Le Mirail
}

Journal of Neurolinguistics, 17 (1), 3-30.

\begin{abstract}
The aim of this paper is to provide the reader with a general overview of the field of attrition. Having situated this relatively new research domain with respect to related fields and approaches, a brief summary of the most important research questions and preliminary findings is given. The discussion then focuses on two issues that are of particular interest with respect to neurolinguistics: the role of the subject's age and of the influence of L2. Concerning the former, a summary of research on the critical period hypothesis is given and discussed in the light of findings from attrition research. Another issue concerns the principal mechanisms involved in L1 attrition, i.e. whether attrition occurs because of lack of L1 use or because of its replacement by the competing L2 structures. Research issues of such scope need integrative approaches and greatly benefit from comparisons with related fields such as normal aging, acquisition and aphasia.
\end{abstract}

Keywords: bilingualism, attrition, neuropsycholinguistics, critical period, interference 
Attrition can be defined as the non pathological loss of a language in, usually, bilingual subjects. From an epistemological point of view, it can be seen as a subfield of contact linguistics (e.g., Goebl, Nelde, Stary \& Wölck, 1996; Myers-Scotton, 2002), but it should be distinguished from sociolinguistic contact phenomena such as language change, shift, loss and death in bilingual communities. It is generally assumed that, like shift, attrition is a 'negative' consequence of language contact ${ }^{\mathrm{i}}$, leading to loss on either the form or function level. However, language change, shift and death typically take place in bilingual communities across generations, whereas the term 'attrition' is used to refer to individual language loss and consequently takes place within one generation (de Bot, 2001). Furthermore, 'attrition' can be defined as loss of the structural aspects of language, i.e. change or reduction in form, whilst 'shift' is a loss of functional aspects, i.e. the gradual replacement of one language by another with respect to language use (Clyne, 1986, 2001). It is this focus on structural aspects in individual language loss that makes the attrition field so promising for multidisciplinary approaches: besides its obvious sociolinguistic dimension, attrition also allows the testing of linguistic hypotheses and psycholinguistic models of the interaction of two languages in the human brain/mind, and it thus finds a natural place within the field of neurolinguistics, completing the picture of language deterioration along with the data from L1 loss in healthy aging and pathological loss in aphasia or dementia. Particularly, psycholinguistic data on attrition are crucially needed in order to have a more comprehensive understanding of premorbid linguistic competence in multilinguals. Conversely, attrition research will benefit very much from taking neurolinguistic models into account since the mechanisms underlying attrition might well be related to general brain functioning.

The main research questions raised by these different disciplines can be summarized as follows:

(a) Why does attrition occur? Most attention has been paid to external factors which influence attrition such as age (discussed below), education level (e.g., Jaspaert \& Kroon, 1989; Yagmur, 1997), emigration length (e.g., Ammerlaan, 1996; de Bot, Gommans \& Rossing, 1991; Hutz, 2004), or amount of contact with L1 (e.g., de Bot et al., 1991; Köpke, 1999). Some studies have attempted to integrate these factors within larger sociolinguistic frameworks, e.g., Ethnolinguistic Vitality Theory (Hulsen, 2000; Yagmur, 1997) or Social Network Theory (Hulsen, 2000), the findings, however, have so far been inconclusive. More recently, internal factors for language attrition such as emotion (Dewaele, 2004; Pavlenko, 2002a; Schmid, 2002, 2004) or attitudes and motivation (Köpke, 2000) have received some attention with promising results that clearly call for further investigation.

(b) What kind of structure is affected by attrition? Are some linguistic features more vulnerable than others? Indisputably, attrition is selective (cf. Seliger, 1991: 228) and does not concern all aspects of language in the same way. This question has mostly been addressed in broad linguistic investigations focusing either on intralanguage effects (simplification, overgeneralization) or on interlanguage effects (cross-linguistic influence), but despite a growing number of studies within this perspective, research is still rather inconsistent and lacks coherence (see Köpke \& Schmid, 2004, for a more detailed discussion and references). Only recently have specific theoretical frameworks been used more systematically, for example Chomsky's Universal Grammar (UG) and minimalism (e.g., Cuza, 2002; Gürel, 2002, this issue; McCormack, 2001; Montrul, 2002; Sorace, 2000) or Myers-Scotton \& Jake's (2000) 4M-Model (e.g., Bolonyai, 1999; Gross, 2000; Schmitt, 2001).

(c) How does attrition occur? This question addresses the nature of the psycholinguistic and neurological mechanisms underlying attrition. This is the aspect the present paper will focus on, since the factors discussed here fall under this question.

Psycholinguistic issues regarding attrition have been theorized since early days of research within the field, e.g., the competence/performance issue discussed in Sharwood Smith (1983a, $1983 \mathrm{~b}, 1989)$, who drew attention to the fact that attrition may, in many cases, involve difficulties in the control of the two linguistic systems rather than actual modification of one system. As Seliger \& Vago (1991: 4) pointed out, "the languages spoken by the bilingual may be said, metaphorically, to coexist in a state of competition for a finite amount of memory and processing space in the mind of the speaker". This view is in line with neurolinguistic frameworks for bilingualism such as Green's Inhibitory Control Model ${ }^{\mathrm{ii}}$ (Green, 1986, 1998) 
or Paradis' Activation Threshold Hypothesis (Paradis, e.g., 1993, 2001) (see Gürel, this issue, for a description). Within such frameworks, processing difficulties (or 'performance attrition')-like delayed lexical retrieval which is frequently observed in L1 attrition (e.g., Ammerlaan, 1996; Olshtain \& Barzilay, 1991) and described in more detail in Goral (this issue) - can be explained on the basis of the raising of activation thresholds for items (or a language) used less frequently (Paradis, 1993: 138), and/or of lack of resources in the less frequently used language (Green, 1986) (for a more detailed discussion of these issues, with respect to attrition, see Gürel, this issue; Köpke, 2002).

It is now widely recognized that bilinguals are not the sum of two unilinguals (Grosjean, 1989). This difference does not have to be ascribed to specific mechanisms for the processing of two languages (Paradis, 1980: 503), but bilinguals have repeatedly been shown to be slower than unilinguals on at least some tasks: e.g., Mack (1983) in naming and lexical decision; Mägiste $(1979,1985)$ in naming, recall and matching; Kilborn (1989) in sentence processing; Segalowitz (1991) in primed lexical decision in the controlled but not in the automatic access condition (see Goral, this issue, for more details), and Soares \& Grosjean (1984) in lexical decision on non-words only (see Green, 2002, for a summary of more recent data). Longer response times in balanced bilinguals can be attributed to lexical access in bilinguals not being selective (e.g., De Bruijn et al., 2001; Green, 2002: 241), but they can also reveal difficulty in the control of two language systems (Green, 1986). In non-balanced bilinguals, longer response times are generally found in the weaker language $\mathrm{e}^{\mathrm{iii}}$ (and are sometimes taken as measures for language balance in bilinguals, e.g., Mägiste 1979, 1985). The weaker, non-dominant language is generally the second language in late bilinguals, but it has long been recognized that even in late bilinguals the dominance pattern can be reversed when language use changes substantially. In this case, response times slow down in L1 as L2 becomes the dominant language (e.g., Frenck-Mestre, 1993; Lachman \& Mistler-Lachman, 1976; Segalowitz, 1991).

The fact that little attention has, so far, been devoted to this point may have two reasons. Firstly, research on bilingualism has probably mostly been carried out on L2 learners for whom the L1 is still dominant, although they are highly proficient in L2. Secondly, researchers have long preferred to avoid the complex issue of L2 interference on L1. Indeed, the 'unilingual' point of view - based on the idea that a bilingual should behave like a unilingual in each language (e.g., the definitions given by Bloomfield, 1933: 56; Thiery, 1976: 52) - has until recently dominated the field. This implies that anybody who does not fit into this idealized picture - which is the case of almost every bilingual-is a 'poor' bilingual, or simply not a bilingual at all. The impact of this point of view is reflected in the continued reluctance to use the term 'attrition' in reference to bilinguals because of its negative overtones (see for example Cook, 2003a; Laufer, 2003).

In the case of a reversal of dominance patterns, however, with L2 gradually becoming the stronger language, bilinguals may reach a point where (a) processing of L1 is not only slowing down but also becoming more and more influenced by L2 (Cook, 2003a; Pavlenko, 2000) and where (b) lack of speed and/or accuracy may eventually lead to difficulties. It is at this point that one generally starts talking about attrition. Needless to say, it is rather difficult-if not impossible-to draw a clear-cut line between 'normal' bilingual competence-adapted to the communicative needs of the speaker - and cases of mild attrition. However, there may be no need at all to make such a distinction: it is, after all, only a question of degree, the mechanisms involved in both cases most likely being the same.

From a neurolinguistic point of view attrition can be seen as part of an integrative approach to language use "across the lifespan" (Hylstenstam \& Obler, 1989), including language decline - be it of a pathological nature, as in aphasia or dementia, or not, as in normal aging or attrition. Theoretical links have been established repeatedly between L1 and L2 acquisition and attrition research (e.g., Gürel, 2002; Montrul, 2002; Platzack, 1998; Sharwood Smith, 1983a; Sharwood Smith \& van Buren, 1991). An important body of research (e.g., Jordens, de Bot, van Os \& Schumans, 1986; Jordens, de Bot \& Trapman, 1989; Kuhberg, 1992; Olshtain, 1989; Schmid, 2002) was conducted within the framework of the Regression Hypothesis - loss as the mirror image of acquisition-, initially proposed by Jakobson (1941) for aphasia and adapted to attrition by de Bot \& Weltens (1991). While it has been clearly demonstrated that the Regression Hypothesis does not hold with respect to 
aphasia (Caramazza \& Zurif, 1978), the idea appears promising for attrition which is progressive in nature, thus allowing for a reversal process in which those items learned last may be forgotten first ${ }^{\mathrm{iv}}$. Empirical evidence concerning this issue is still conflicting. It appears possible, however, that the Regression Hypothesis may yield more promising results for L2 than for L1 attrition (see Köpke \& Schmid, 2004, for more details).

Attrition has also been discussed in relation to polyglot aphasia (e.g., Obler, 1982; Obler \& Mahecha, 1991) and other neurolinguistic aspects of attrition and acquisition (Obler, 1993). Neurolinguistic approaches are, however, still scarce amongst the bulk of attrition research. Two research issues are of particular interest in this perspective at the moment: (a) the question of the role of age at the onset of bilingualism/attrition, and (b) the question of whether L1 attrition is caused by lack of L1 use or rather by the preferential usage of another language, i.e. by influence coming from L2.

The papers in this special issue concern both questions. With respect to the first question, a great variety of ages reaching from early childhood (Ventureyra, Pallier \& Yoo) to elderly speakers (Goral) are covered. As regards the second question, this issue presents a broad range of L1 use patterns including, at each extreme, total disuse of L1 (Ventureyra et al.) and total L1 use (Goral). The aim of the present introductory paper is to give an overview of the state of the art in attrition research pertaining to the two issues previously mentioned: the roles of age and L2 influence. In this context, an extensive discussion of issues such as the Critical Period Hypothesis will be presented.

\section{The role of age in attrition}

Age at the onset of bilingualism and/or attrition ${ }^{v}$ has been found to be one of the most important factors involved in attrition. Köpke \& Schmid (2004) point out that if there is one question in L1 attrition for which there is ample converging evidence, it is that attrition in children is much more severe than in adults. All the studies dealing with L1 attrition in young children (e.g., Bode, 1996; Kaufman, 2001; Kaufman \& Aronoff, 1991; Schmitt, 2001; Seliger, 1989, 1991; Turian \& Altenberg, 1991; Vago, 1991) relate substantial restructuring of the children's linguistic competence ${ }^{\mathrm{vi}}$ far beyond anything that has been observed in adult L1 attrition, unless exceptional traumatic circumstances obtain (Schmid, 2002). Studies investigating adopted children, e.g., Ventureyra et al. (this issue), suggest that in such extreme cases, L1 is 'forgotten' at a very quick rate (Isurin, 2000; Nicoladis \& Grabois, 2002). Some studies also include both subjects who emigrated as children and as adults, allowing for comparisons (e.g., Ammerlaan, 1996; Pelc, 2001). In Ammerlaan's study on lexical retrieval and lexical access among Dutch immigrants in Australia, the subjects' ages of departure varied from 6 to 29 years (see also Goral, this issue, for a more detailed description of this study). Pelc's Greek immigrants were between 8 and 32 years old when they arrived in the United States, with $50 \%$ of the subjects having arrived between 12 and 17 years of age. Attrition was assessed in acceptability and grammaticality judgments of idiomatic verb use, and of gender and case marking. In both studies, age at departure proved to be the most important predictive factor for attrition. On the other hand, in studies involving subjects for whom the onset of attrition was after puberty no age effect was found (e.g., Jaspaert \& Kroon, 1989; Köpke, 1999).

The rather dramatic attrition effects observed in children are in radical contrast to the findings with respect to adults. None of the studies investigating subjects for whom the onset of attrition took place during or after puberty has produced similar results, regardless of the languages involved or the means of data elicitation. In most cases, attrition was felt to be surprisingly mild, considering the amount of time spent in an L2 environment (often many decades). For example, de Bot \& Clyne (1994), Hulsen (2000), Jordens et al. (1989) and Schoenmakers-Klein Gunnewiek (1998) found little or no attrition in first generation immigrants, and in many other studies communication in L1 did not appear to be severely disrupted by attrition (e.g., Altenberg, 1991; de Bot et al., 1991; Hutz, 2004; Jaspaert \& Kroon, 1992; Köpke, 1999; Major, 1992; Olshtain \& Barzilay, 1991). Quantifying the amount of attrition, is, of course, a task that is almost impossible-however, the overall picture revealed by attrition research on adults is quite different from the one which emerges from 
research on children. As an example, in Köpke (2001) I described in more detail one subject (E-44) from my larger 1999 study (cf. the summary in Goral, this issue) who seems to illustrate a certain type of 'adult' attrition. This 64-year-old man had been living in Canada for 39 years at the time of data-collection. He claimed he never spoke German, never went back to Germany and preferred English in any situation. He talked mostly English with the researcher (despite her keeping to German), but nevertheless agreed to participate in a formal test in German consisting of picture descriptions, sentence generation and grammaticality judgments. The results showed difficulties in lexical retrieval in spontaneous speech and problems with prepositions. On the other hand, there were hardly any grammatical errors in his oral production, neither in the picture description nor in the time-constrained sentencegeneration task. The judgment of ungrammatical L1 sentences that are grammatical in L2 was above average with respect to the rest of the group (for more details, see Köpke, 1999, 2001). As soon as the test was over, the subject switched back to English. What is striking with this case is the contrast between the subject's obvious strong discomfort in L1 and his relatively well preserved L1 competence regarding grammar, as evidenced by a formal language test involving no conversational skills. This rather anecdotal evidence suggests that in such cases, attrition consists mainly of the inaccessibility of L1 rendering conversation in this language very arduous while the underlying linguistic competence remains intact, even after such a long period of L1 disuse. Similar findings come from many other studies with late bilinguals (e.g., de Bot \& Clyne, 1994; Jaspaert \& Kroon, 1992; Schoenmakers-Klein Gunnewiek, 1998).

In order to sum up the differences in attrition between children and adults, it is worth looking at Sharwood Smith's three stage framework (Sharwood Smith, 1983b: 51). The three stages in the evolution of attrition are established with respect to the competence/performance distinction. The first stage is characterized by deviations in performance while competence remains stable. In the second transitional stage, the speaker "is in possession of a new externally conditioned variety of his or her language [...] but is able to switch back to standard versions of the language when the appropriate circumstances require it" (Sharwood Smith, 1983a: 51). It is only the third stage which marks the advent of a new, modified competence. While such restructured linguistic systems have not yet been described for late attriters, they have repeatedly been observed in children (e.g., Kaufman \& Aronoff, 1991; Seliger, 1989, 1991). As regards late bilinguals, the evidence suggests that attrition is, in most cases, restricted to performance deviations as in stage 1 . In some cases-whether under specific external conditions or regarding particular linguistic features or domains -it might be possible to observe the coexistence of two varieties as described in stage 2, which Major (1992) observed for phonetics. More systematic investigation is called for in relation to this issue.

We have seen, however, that the differential effects of attrition on children and adults are amply documented. This finding is generally linked to some variant of the Critical Period Hypothesis $(\mathrm{CPH})$ since it is assumed that younger children are better L2 learners due to maturational constraints and, consequently, more readily forget their L1 (see also Ventureyra et al., this issue). Such maturational constraints can be either of a biological or of a cognitive nature. Since attrition and acquisition seem to be tightly linked, and since the question of a critical period is an essential issue at the present state of attrition research, the literature on the $\mathrm{CPH}$ for language acquisition will be reviewed in some detail here.

\subsection{Biological factors related to age}

There are few issues which have been as extensively debated as the $\mathrm{CPH}$ for first and second language acquisition. Since the CPH was extended to language by Penfield \& Roberts (1959) and Lenneberg (1967), it has continually confronted proponents and opponents, and the huge number of recent analyses of the issue (e.g., Birdsong, 1999; Birdsong \& Molis, 2001; Hakuta, Bialystok \& Wiley, 2003; DeKeyser, 2000; Mack, 2002; Moskovsky, 2002) shows that the debate is far from resolved. However, the ideas are becoming clearer; for example, it has been repeatedly suggested that one should not confuse L1 and L2 acquisition (e.g., Moskovsky, 2002; Zobl, 1995). 


\subsubsection{L1 acquisition}

With respect to L1 acquisition, two factors related to brain maturation have been put forward to explain the child's greater aptitude for language learning: lateralization and plasticity. Lenneberg (1967: 179) argued that the critical period (CP) for language acquisition reaches its term with the establishment of cerebral laterality around puberty. Evidence from children with acquired aphasia, which suggested that younger, as opposed to older, children suffering from brain damage were able to recover their language ability, had been attributed to greater brain plasticity at a younger age (Penfield \& Roberts, 1959). Both arguments have been severely questioned in recent years: Converging evidence suggests that lateralization is completed well before puberty (cf. Archibald \& Libben, 1995: 291; De Agostini, 2002: 174/175; Harley \& Wang, 1997: 23); with respect to aphasia, De Agostini (2002: 177) concluded that hemispheric lesions in children past three years of age have the same consequences as those observed in adults. Consequently, if there were a biological $\mathrm{CP}$, it would end much earlier than at puberty (see also Paradis, 2003).

Despite the absence of broad empirical evidence, it appears nevertheless very likely that a child who is not acquiring language in the first years will have difficulties in attaining mature linguistic competence later on. It has been argued (e.g., Archibald \& Libben, 1995: 306) that cases of late L1 acquisition in linguistically isolated children such as Genie (Curtiss, 1977) cannot be taken as evidence for a CP. Indeed, these children have not only been linguistically isolated but suffer also from sensorial, social and affective deprivation, the cognitive consequences of which are not exactly known. There are also some cases of deaf children with delayed L1 acquisition, who grew up in otherwise normal circumstances, showing severe deficits in verbal comprehension and production, which supports the CPH (e.g., Grimshaw, Adelstein, Bryden \& MacKinnon,1998). For the attrition issue, however, the question of a CP for L2 acquisition is by far more relevant.

\subsubsection{L2 learning}

Where this issue is concerned, a CP for subsequent languages cannot be taken as a logical consequence of a CP for L1 acquisition, even if this has been repeatedly claimed to be the case (cf. Moskovsky, 2002: 2). The most frequently raised arguments supporting or invalidating the $\mathrm{CPH}$ for $\mathrm{L} 2$ can be summarized as follows (for more extensive reviews of this abundant literature, see e.g., Birdsong, 1999; Harley \& Wang, 1997; Long, 1993; Moskovsky, 2002):

(a) The question of ultimate attainment. It is generally assumed that late L2 learners are no longer able to acquire native-like competence. Consequently, the existence of subjects who do attain native-like competence is taken as an argument against the $\mathrm{CPH}$. This assumption has been challenged by many authors, which has enabled the evidencing of some cases of nativelike ultimate attainment in late bilinguals (see Birdsong \& Molis, 2001, for more details).

(b) The question of acquisition rate has been taken as evidence against the $\mathrm{CPH}$. It has been shown that late learners learn faster than young learners: adults are faster than children (namely with respect to morphology and syntax) and older children are faster than younger ones (Long, 1993: 198). Younger learners, however, outperform older learners eventually with respect to ultimate attainment.

(c) The presence of postmaturational age effects. A biologically constrained CP, it is argued, would imply that there is some critical age after which the ability to learn a language (or specific aspects of it) suddenly and permanently changes. This would result in (a) a marked decline with respect to ultimate attainment after this age, and (b) absence of further age effects once the CP is over. This, however, is not the case. Hakuta et al. (2003) analyzed U.S. Census data from 2.3 million immigrants with Spanish or Chinese language backgrounds in relation to the first prediction. The results failed to prove any discontinuity with respect to the age effects substantiating the idea of a CP. As far as the second prediction is concerned, postmaturational age effects have been repeatedly evidenced, in Hakuta et al.'s study and in many others (see Birdsong \& Molis, 2001, for a review).

(d) It has, furthermore, been suggested that the CPH might apply differently to distinct linguistic domains. For example Walsh \& Diller (cited by Archibald \& Libben, 1995: 291) proposed a biological explanation focusing on pronunciation (1981: 18): 
"Lower-order processes such as pronunciation are dependent on early maturing and less adaptive macroneural circuits, which makes foreign accents difficult to overcome after childhood. Higher-order language functions, such as semantic relations, are more dependent on late-maturing neural circuits, which may explain why a college student can learn many times the amount of grammar and vocabulary than elementary school students can learn in a given period of time."

There seems to be a general consensus that pronunciation is most affected by the age of acquisition since there are very few late learners who achieve native-like pronunciation (cf. the more detailed discussion of this aspect in Ventureyra et al., this issue). Morpho-syntax is also generally seen to be a good candidate for CP effects, whereas lexical and semantic knowledge is less likely to be affected by age. This corresponds to acquisition rate: while the acquisition of L1 pronunciation and morpho-syntax is accomplished within the first years of age, vocabulary learning goes on throughout life and should not be that different in nature for L1 or subsequent languages. Concerning semantics, Pavlenko (2002b: 79) points out that "[n]umerous cases of successful second language acquisition demonstrate that concepts may be restructured in the process of second language learning and socialization..." Age effects have been found repeatedly for both pronunciation and morpho-syntax but it should be noted that in both cases age effects were linear, without any discontinuity which is claimed to be characteristic of a biologically constrained CP (Long, 1993).

(e) Evidence from brain imaging techniques. The L1 and L2 of late bilinguals have been shown to exhibit differences in brain activation patterns in studies based on tasks involving grammatical processing (e.g., with ERP: Hahne \& Friederici, 2001; Weber-Fox \& Neville, 1996; and fMRI: Kim, Relkin, Lee \& Hirsch, 1997; Perani, Dehaene, Grassi, Cohen, Cappa, Dupoux, Fazio \& Mehler, 1996). Similar differences have not been observed between the two languages of early bilinguals. In semantic processing, on the other hand, no differences were found between L1 and L2 of early and late bilinguals (e.g., Hahne \& Friederici, 2001; Klein, Zatorre, Milner, Meyer \& Evans, 1995; Weber-Fox \& Neville, 1996). This implies that L1 and L2 are processed in the same cerebral locations except for grammatical processing in late bilinguals. Such findings (see Goral, Levy \& Obler, 2002; Ullman 2001, for more comprehensive reviews) underscore that if certain brain locations were no longer available for linguistic acquisition after a $\mathrm{CP}$, this would concern grammar only but not semantics (cf. Köpke, 2002).

Considering this evidence, it is unlikely that a strong hypothesis of a $\mathrm{CP}$ due to maturational constraints on the brain will hold with respect to L2 acquisition. Generally, younger learners achieve better levels of ultimate attainment than older learners, but there is no evidence for a 'fateful' age after which the brain is no longer responsive to linguistic learning, making further language learning impossible. It is, however, not unlikely that there are cognitive factors changing the way language is learned with increasing age, which could also explain the differences in grammatical processing of L2 between early and late learners as observed with brain imaging techniques.

\subsection{Cognitive factors related to age}

Second language learners clearly differ from first language acquirers as regards several cognitive factors. I will briefly discuss two of them here: general maturity and literacy.

\subsubsection{Cognitive maturity}

It is evident that the cognitive maturity of a child is different at the ages of, say, two and twelve. Infants learn about the world at the same time as acquiring language and L1 acquisition is inextricably linked with the acquisition of all the other cognitive functions such as reasoning, memory, attention, and even learning. Therefore, whatever the external circumstances of L2 acquisition, whatever the cognitive style of the learner: even the most holistic L2 learners in a perfectly natural L2 setting will nevertheless learn L2 differently from L1, since it is not the first time they acquire a language and because their general knowledge about the world has considerably changed since infancy. Furthermore, they have already acquired a language that will have some influence on subsequent language learning (the 
consequences of this fact for attrition will be discussed below). Even in simultaneous bilinguals, one language might nevertheless, at times, be acquired through the 'cognitive sieve' of the other language, since the child does not always progress in the same way in both languages.

One could however argue that it does make a difference if the child, when starting to learn an L2, cannot continue using L1 at all, in other words, if learning L2 is the only means of communication, as is generally the case in adopted children (see Ventureyra et al., this issue). Even such an extreme situation will, however, only change the child's motivation, his cognitive maturity remaining the same. Consequently, even an adopted child who completely changes his linguistic environment by age 8, for example, will learn L2 like an 8-year-old child and not like an infant.

Such a difference in cognitive maturity between early and late language learners suggests that L1 and L2 learning might employ qualitatively different processes, an assumption that led to a number of attempts to capture such a potential diversity. The first is Krashen's (1981) distinction between 'acquisition' and 'learning', which due to theoretical flaws in Krashen's monitor model $\mathrm{l}^{\mathrm{vii}}$ has not received the attention it deserves ${ }^{\text {viii }}$ (cf. Zobl, 1995, for a discussion). The two processes are distinguished both by the manner of internalization of linguistic knowledge and by the representation in memory of that knowledge: as summarized by Zobl (1995: 35): “'Acquisition' operates incidentally to processing for comprehension and results in implicit, intuitive knowledge; 'learning' relies on memorization and problem-solving and leads to explicit, conscious knowledge about the L2."

This point has also been raised by Paradis (1994) who claims that L1 is subserved by procedural or implicit memory whereas formally learned L2s are subserved by declarative or explicit memory, both of which form neurofunctionally and anatomically distinct memory systems (see Paradis, 1994, and Ullman, 2001, for detailed descriptions of both memory systems). Paradis' position, however, appears to be less 'black and white' than Krashen's or Zobl's. Indeed, Paradis considers that both types of knowledge-procedural and declarativeparticipate in both L1 and L2 processing to different extents, depending on the speaker's educational level (i.e. the extent of his declarative knowledge with respect to L1 and L2), the way he learned L2 (i.e. in a naturalistic way or via formal instruction), the 'formality' of the conversational setting, etc. Consequently, the proportion of L2 represented in explicit memory should depend on the formality of L2 learning. On the other hand, Paradis states that "there is increasing evidence that cerebral plasticity for the implicit acquisition of phonology and morpho-syntax decreases with age" (1994: 413) which would lead to greater reliance on explicit memory structures in late learners. Note that both Paradis (1994: 402) and Zobl (1995: 38) assume that explicit knowledge cannot become implicit competence: Repeated practice of metalinguistically-governed speech may eventually bring about the development of some implicit knowledge, but this is distinct from the declarative rules known by the learner and relies on implicit memory which is less accessible at a more advanced age.

A similar position is taken by Bley-Vroman (1989) who claims that the CPH is not applicable to L2, since L1 acquisition and L2 learning rely on two fundamentally different processes (the Fundamental Difference Hypothesis, cf. also Moskovsky, 2002). In view of the fact that there are many differences between both types of language 'appropriation' ${ }^{\text {,ix }}$ she suggests that both involve different linguistic knowledge bases and different cognitive procedures. L1 acquisition would be based on UG and a set of domain-specific learning procedures (Chomsky's legendary Language Acquisition Device); L2 learning, on the other hand, would rely on the learner's L1 as a linguistic knowledge base and on general cognitive learning procedures (cf. Zobl's 1995 position). Here the debate of whether there is a CP for L2 learning joins the equally extensive debate of whether UG is accessible to L2 learners. This question, however, cannot be developed further here, see Gürel (2002) and the references therein for a summary.

In sum, it has often been suggested that L1 acquisition and L2 learning involve different cognitive procedures that are in part dependent on cognitive maturity (see also Obler, $1993^{\mathrm{x}}$ ).

The distinction between implicit and explicit memory that emerges from this discussion provides a highly promising starting position for attrition research. The issue of forgetting has actually been mentioned in this context by Zobl (1995: 38) who points out that "[i]mplicit memory requires no conscious or awareful attempt at retrieval (Schacter, 1985) and is more 
resistant to forgetting (Nilsson and Baeckman, 1989)." If L1 were indeed part of implicit and L2 of explicit memory, it would be more resistant to attrition in adults than L2. Not only is interference less likely to occur between structures that are part of different memory systems, but implicit L1 knowledge would by nature be less prone to attrition than explicit L2 knowledge. While there is no experimental evidence supporting the claim that adult bilinguals forget an L2 more easily than an L1, there is evidence suggesting that L1 is quite resistant to attrition in late bilinguals. As one of Ammerlaan's subjects put it: "My Dutch is like riding a bike. You never forget it but you get a bit wobbly." (Ammerlaan, 1996: dedication).

It should, however, be recalled that implicit knowledge apparently is not as resistant to attrition from the beginning, since young children have been shown to be more sensitive at this level. Thus the question as to when the L1 will be sufficiently established to become immune to forgetting remains, as well as the issue of what kind of factors contribute to this establishment. I would like to suggest that literacy might be one of these.

\subsubsection{Literacy}

While it has been suggested that a change in vulnerability to attrition takes place around the age of 9 (e.g., Köpke \& Schmid, 2004 Yoshitomi, 1992), empirical evidence for such a claim comes, for the moment, from L2 attrition only (e.g., Berman \& Olshtain, 1983; Fujita, 2002; Olshtain, 1989). Olshtain (1989), for example, observed a reversal of the acquisition of irregular forms of noun plurals and verb forms in the past tense in a younger group of Hebrew-English bilinguals (5-8 year olds) but not in an older group of subjects (8-14 year olds). One of the characteristics of children, from this age onwards, is that, as opposed to younger children, they are generally perfectly literate. This factor has not received much attention until now. Only Pan \& Gleason (1986: 197) have suggested that literacy might be a major variable for language maintenance in children, while Olshtain (1989: 154) claimed that age interacts with literacy (in children) and cannot be considered independently. Regarding L1 attrition, only age effects have been noted so far; these clearly need to be put in relation with literacy.

Literacy may indeed have more than one impact on attrition. First of all, literacy enables the child to stay in contact with the language via books or written correspondence. Olshtain (1989) hypothesized that this kind of contact might compensate for the lack of spoken English input in her older subjects (8-14 years old). These subjects actually reported continuing the expansion of L2 vocabulary via reading (Olshtain, 1989: 163). Literacy might thus provide the attriter with the possibility of obtaining enough confirming evidence to maintain linguistic features which contrast with the language used dominantly. Written input could indeed be a sufficient source of language, especially for late bilinguals for whom L1 was completely developed and fixed before the onset of attrition.

Secondly, the knowledge of a written code might enhance the perceived prestige of a language, thus increasing motivation for its maintenance (Christian, 1977). With respect to language learning, the crucial role of motivation has long been recognized (Gardner \& Lambert, 1972) and similar observations obtain for some cases of polyglot language recovery following aphasia (Minkowski, 1928). Concerning attrition, it has been hypothesized that motivation and attitudes play a similar role (Dewaele, 2004; Gardner, 1982; Yoshitomi, 1992), but the most compelling evidence is doubtless provided by Schmid's (2002) data: Schmid analyzed interviews conducted with German Jews who left Germany between 1933 and 1939 and found that the most important factor influencing L1 attrition was the period of emigration, which outweighed other variables such as age at emigration and contact with L1. Schmid explains this result by the fact that subjects who stayed longer in Germany suffered more from persecution, which created negative attitudes to German and lead the subjects to deliberately reject their L1. Children, even at a very young age, are highly sensitive to the perceived value of a language. The written code is generally perceived as a highly valuable 'object' by children and a language used for reading and writing is felt to have a higher prestige than a language used orally only. It is thus very likely that literacy influences their motivation to maintain a minority language (e.g., Ó Laoire, 2002; Yoshida, 2002).

Finally, it has been hypothesized that literacy might influence the neuroanatomical and/or neurofunctional representation of language. Lecours, Mehler, Parente \& collaborators (1988) point out that the role of the acquisition of reading and writing skills for the full actualization 
of the functional lateralization potential is not yet known. On the basis of more variable aphasia patterns observed in illiterates, it has repeatedly been suggested that literacy plays a major role in cerebral dominance, (e.g., Wechsler, 1976; Métellus, Cathala, Issartier \& Bodak, 1981). These findings have not, however, been corroborated by dichotic listening studies (see Lecours et al., 1988 for a review), nor by broader group studies (Damasio, Castro-Caldas, Grosso \& Ferro, 1976). The findings from Lecours et al.'s (1987, 1988) large-scale study remained somewhat inconclusive with respect to this issue, which is in part due to difficulties with the use of common aphasia tests among illiterate populations. The lateralization issue notwithstanding, one might hypothesize that a language is not fixed as firmly in the memory of an illiterate person, all the more so if that person is a child. Whichever theoretical background one adopts, psycholinguistically, becoming literate in a language generates a second body of representations and/or connections to the oral representation the subject has already acquired. For languages with an alphabetic code, a reading beginner may manage with simple grapheme-phoneme conversion, but later on the child will have to build up an orthographic lexicon (be it in the form of an independent module or of additional connections). Such additional representations, along with the connections that will be established between oral and written representations, should contribute considerably to the grounding of the language. It can be argued that even in illiterate children, continued use of a language and growing automaticity (cf. also Goral, this issue) does increase the weight of the connections, however, literacy may speed up such a process.

In the case of L2 attrition, it has been argued that the 'degree of stability of L2 knowledge' contributes to language maintenance (e.g., Moorcroft \& Gardner, 1982; Yoshitomi, 1992). The role of literacy in this context still needs to be investigated. The establishment of a linguistic system may depend on a multitude of factors such as increasing language experience, cognitive maturity and its influence on the use of different memory systems, etc. In which way literacy contributes to this interplay should, however, be elucidated.

\subsection{Conclusion}

First of all, it should be emphasized that learning how to speak (in any language) and learning subsequent languages involves distinct processes. While there are probably biological constraints for the acquisition of an L1, we have seen that most of the evidence indicates that a strong, biological version of the $\mathrm{CPH}$ does not hold with respect to L2 learning. It has been suggested that L1 acquisition and subsequent L2 learning rely on different memory systems (Paradis, 1994) and involve qualitatively different processes (BleyVroman, 1989; Zobl, 1995) which could explain why the CPH applies to L1 acquisitionlargely based on implicit memory -, while it does not hold with respect to L2 learning which is more dependent on explicit memory. Unfortunately, this has not sufficiently been taken into account in the $\mathrm{CPH}$ literature.

However, some authors suggest more moderate alternatives of the $\mathrm{CPH}$ with more emphasis on cognitive than biological factors. Harley \& Wang (1997), for example, prefer to refer to a 'sensitive period' which gradually declines with increasing age. This hypothesis has the advantage of being compatible with the absence of a sudden decline in learning ability and with ongoing age effects in adults. Similarly, Mack (2002: 162) suggests there is an initial CP during which language learning is optimal. This period (which may vary in length across different linguistic domains) is followed by a gradually declining sensitive period where language learning is still possible, though no longer optimal. Hakuta et al.'s claim (2003: 5) goes even further:

"An alternative interpretation to the critical period hypothesis is that second

language learning becomes compromised with age, potentially because of factors not specific to language that nevertheless interfere with the individual's ability to learn a new language. These might include social and educational variables that influence learning potential and opportunity, and cognitive aging that gradually erodes some of the mechanisms necessary for learning a complex body of knowledge, such as a new language."

This claim is in line with the view that language learning depends on cognitive factors that are age-dependent, such as general maturity (including, for example, memory performance, 
attention, reasoning, general experience etc.). Literacy certainly plays some role in the development of at least some cognitive aspects, but this issue clearly needs further investigation. Moreover, one of the most important factors involved in language learning and attrition is motivation-including its consequences on the involvement of the limbic system (see Paradis, 1994; Schumann, 1998).Unfortunately, emotional factors have not yet received much attention. It is, however, possible that such factors may help differentiate between 'normal' attrition in immigrant settings and language replacement in adopted children, for whom L2 communication is essential.

In contrast to the previously prevalent position which considered L1 competence as completely immutable, more recent attrition research tends to show that forgetting a language is frequently assumed to be a logical consequence of the acquisition of another language. It must nevertheless be kept in mind that balanced bilingualism does exist and that no relationship whatsoever between L2 level and L1 attrition has been demonstrated to date. In contrast, it seems to have been just as frequently assumed that attrition is not necessarily dependent on L2 attainment, which is therefore generally not assessed in L1 attrition studies. Such inconsistencies show that the consequences of possible maturational constraints on L2 acquisition with respect to L1 attrition are far from being clear. Moreover, it is only acknowledged exceptionally that L1 and L2 processing might involve qualitatively different processes and memory systems, which undoubtedly has consequences not only for acquisition but also for attrition.

In summary, findings suggest that in children, who are still at an age enabling them to acquire languages incidentally, languages may, within short periods, replace each other if the environmental setting incites the child to do so. With increasing age, the linguistic knowledge of children is becoming more and more stable (for reasons that need to be further explored) and, additionally, due to growing cognitive maturity, explicit learning tends, more and more, to replace implicit acquisition. Consequently, an L2 learned later in life is more dependent on explicit memory than an L1 which has been stored implicitly. This gives rise to the question to what extent a language that has been learned later in life may have some influence on a formerly learned language.

\section{Lack of use versus L2 influence}

There are two possible cognitive processes which may lead to attrition:

a) The memory traces of a no longer used language 'fade away', as suggested by trace decay theories (Ebbinghaus, 1885) which claim that lack of use gradually leads to the extinction of a memory trace ${ }^{\mathrm{xi}}$.

b) Language information is modified under the influence of another language as predicted by Interference theory (Loftus, 1980; Underwood, 1957) which indicates that new information influences previous information (retroactive interference) that is similar in nature and vice versa (proactive interference).

The extinction of traces would be expected in the case in which a subject completely stops using language or a language. This, however, is hardly ever the case. In healthy unilingual aging, there is no reason for a reduction in language use, except with respect to particular discourse domains requiring specific vocabulary or registers which might be less frequently used (after retirement, for example). Even in the rather hypothetical desert island situation outlined by Sharwood Smith \& Van Buren (1991: 22) and de Bot (2001: 68), one can assume that the subject will continue 'talking to himself'. The outcome of such a situation remains in any case mere speculation. In unilingual aging, it is suggested that attrition is due more to decline in cognitive abilities (see Goral, this issue, for more details) than to language internal reasons.

Interference is most likely to occur in bilingual attrition. In the typical bilingual attrition setting, i.e. among migrants, L1 is replaced by L2 in most communication domains, and L2 is thus generally thought to strongly influence the attrition process. A large proportion of L1 attrition studies are based on the cross-linguistic-influence (CLI) hypothesis (Sharwood Smith, 1983a). Pavlenko (2003: 34), for example, defines attrition as the "loss of (or inability to produce) some L1 elements due to L2 influence". Interference from L2 can also be 
explained by the interplay of language use and activation patterns. Even if the Activation Threshold Hypothesis (ATH) (Paradis, 1993, 2001), for example, predicts loss of accessibility as a consequence of disuse, it can be hypothesized that more frequently used competing L2 items will influence L1 processing: for example, L1 items with a high activation threshold will be even more difficult to activate if there are L2 items with a very low activation threshold ready to 'fire', than if there are not (see Gürel, this issue; Köpke, 2002, for a more detailed discussion of the ATH with respect to attrition). However, both frameworks, the Interference Theory and the ATH, can only apply if the interfering or competing information is similar in nature. As we have already seen, this might not always be the case for first and second languages ${ }^{\mathrm{xii}}$.

While crosslinguistic influence from L1 on L2 played a major role in the first decades of L2 learning research (e.g., Lado, 1957; Selinker, 1969; Weinreich, 1953), L2 influence on L1 in the context of bilingualism has only very recently been taken into consideration (e.g., Cook, 2003; Pavlenko, 2000). It should be noted that studies published on the basis of this latter approach adopt Cook's multi-competence framework for bilingualism (e.g., Cook, 1992, 2003a) and explicitly avoid the term 'attrition'. It is argued (e.g., Laufer, 2003; Jarvis, 2003) that the subjects under investigation cannot be considered as suffering from attrition, since their command of L1-despite the measured L2 influence-still allows satisfactory communication. This does, however, seem to be the case for many subjects involved in attrition studies: as Köpke \& Schmid (2004) have pointed out recently, the empirical findings gathered up to now cannot even indicate whether L1 attrition exists at all in adult late bilinguals. I will, therefore, not distinguish between the two types of studies in what follows. As mentioned above, I assume that the underlying mechanisms are likely to be the same, whether the subjects still feel comfortable in L1 communication or not.

\subsection{Empirical data of L2 influence on attrition}

The large number of empirical studies which have investigated L2 influence in L1 attrition has enabled the observation of L2 interference in all linguistic domains: phonetics (Major, 1992; Ventureyra et al., this issue); morphophonology (Vago, 1991); morphology (Altenberg, 1991; Kaufman \& Aronoff, 1991; Seliger, 1991); syntax (e.g., Altenberg, 1991; Bouba, Filiaci, Heycock, Sorace \& Tsimpli, 2002; Grosjean \& Py, 1991; Gürel, 2002; Isurin, 2000; Köpke, 1999; Montrul, 2002; Schmid, 2002; Seliger, 1991; Yagmur, 1997); lexicon (Ammerlaan, 1996; Olshtain \& Barzilay, 1991; Yagmur, 1997); semantics (e.g., Ben Rafael, 2001; Jaspaert \& Kroon, 1992; Pavlenko, 2000; Pelc, 2001). The observations concern a great variety of language combinations (L1-L2) with a large range of typological distances from closely related to largely unrelated language pairs: for example German-English (Altenberg, 1991; Köpke, 1999; Schmid, 2002), Dutch-English (Ammerlaan, 1996; Jaspaert \& Kroon, 1992), Russian-English (Pavlenko, 2000), Turkish-English (Gürel, 2002; Yagmur, 1997), Greek-English (Bouba et al., 2002; Pelc, 2001), Italian-English (Bouba et al., 2002), FinnishEnglish (Jarvis 2003), Spanish-English (Cuza, 2002; Montrul, 2002), Hebrew-English (Kaufman \& Aronoff, 1991), Hungarian-Hebrew (Vago, 1991), French-Hebrew (Ben Rafael, 2001), English-Hebrew (Laufer, 2003; Seliger, 1991), Spanish-French (Grosjean \& Py, 1991), German-French (Köpke, 1999), English-Brazilian (Major, 1992), and Korean-French (Pallier, Dehaene, Poline, LeBihan, Argenti, Dupoux \& Mehler, 2003; Ventureyra et al., this issue), among others.

Once again, the findings are more clear-cut in L1 attrition studies investigating children. Kaufman \& Aronoff (1991: 187) report on the "incorporation of L1 into L2" with respect to morphology in a 2 to 4-year-old Hebrew-English bilingual. In other words, L1, i.e. the remains of it - mostly isolated lexical items in this case-, is integrated into L2 which is becoming more and more the dominant language system. Seliger (1991:239) observes that "Hebrew word order rules for the placement of the PP are combined with and partially replace the English rules..." in a 9-year-old English-Hebrew bilingual; Sharwood Smith (1983a) reports on two student investigations where errors in adverbial placement which could only be ascribed to L2 influence were observed in English-Dutch bilingual teenagers. These findings lead Sharwood Smith to claim that L2 transfer is a fundamental process in attrition (Sharwood Smith, 1983a: 229). 
Concerning adults, in most studies that do find evidence for attrition, the authors attribute attrition effects to interference from L2: for example, Major (1992) who measured VOTs in colloquial English speech that were close to L2 (Brazilian) standards, and several authors reporting on syntactic calques (e.g., Grosjean \& Py, 1991; Hutz, 2004; Yagmur, 1997). The linguistic domain in which most L2 influence has been reported is doubtlessly the lexicosemantic domain. Most authors have observed borrowings and semantic adaptations (cf. examples in Ben Rafael, 2001; Hutz, 2004; Jaspaert \& Kroon, 1992; among others). L1 lexical retrieval also was found to be influenced by L2 characteristics (Ammerlaan, 1996). However, L2 influence is not the only way to interpret the data in all cases. For example, concerning Major's VOT study (Major, 1992), it can be argued that the Brazilian VOT standards simply represent the less marked variety compared to English. Similarly, as Schmid (2002: 13) points out, with respect to syntax or morphology, it is often impossible to conclude whether attrition is more influenced by external (L2) or internal (simplification) factors, since most attrition studies investigated an analytical language (English) as L2.

Four studies have tried to overcome such difficulties by developing a methodology aimed at measuring L2 influence. Schoenmakers-Klein Gunnewiek (1998) and Köpke (1999) both contrasted two groups of immigrants with the same L1 and different L2s. SchoenmakersKlein Gunnewiek (1998) investigated Portuguese immigrants in the Netherlands and in France and focused on semantic interference from the L2. Since her informants on the whole showed only very little interference, the findings were not conclusive for the influence of L2 semantics $^{\text {xiii }}$. In Köpke (1999), I investigated morpho-syntactic L2 interference among German immigrants in France and in Canada by building up linguistic material contrasting either German and English or German and French. This material was tested in three tasks: picture description, sentence generation and grammaticality judgment. It was expected that the immigrants would have most difficulties with L1 structures contrasting with their L2. Such L2 interference was most obvious in the grammaticality judgments. However, even in this task, L2 interference was not the only source of errors (see Goral, this issue, for further description of this study). Altenberg (1991) used a similar technique in a pilot study with two German-English bilinguals. The linguistic material for a grammaticality judgment task was calqued either on L2, or on Spanish, a language the subjects did not know at all. The results showed that ungrammatical L1 sentences which were grammatical in L2 were judged more acceptable than sentences which were ungrammatical in L1 and L2 ${ }^{\text {xiv }}$. Pelc (2001) obtained similar results with the same methodology for the judgment of verb-usage in a group of Greek-English bilinguals.

In sum, these studies nevertheless support the hypothesis that transfer from L2 is a fundamental process in attrition, as was claimed by Sharwood Smith (1983a: 229). Interestingly, they furthermore suggest that interference is all the more likely as structures are similar in both languages. Similarity may be phonological or structural or both (as is frequently the case in closely related languages like English and German). Altenberg even concluded that L1 and L2 similarity is a necessary condition for transfer. This is in line with what was stated above with respect to interference theory.

\subsection{Amount of contact with L1}

Another way to investigate whether attrition is due to L2 influence or to lack of use is to examine the role of the amount of contact the subject has maintained with L1. This factor is generally assumed to be essential, since it is linked to frequency of L1 use which should be a key variable following activation/inhibition based frameworks like the Activation Threshold Hypothesis (Paradis, e.g., 1993, 2001). In many studies this factor has been crucial in the selection of participants who form a homogenous group at this level, but some studies allow for further investigation. Among these, de Bot et al. (1991) and Köpke (1999) found that attrition was greater in subjects who had less contact with L1, whereas Jaspaert \& Kroon (1989) found no correlation between attrition and the amount of contact in Italian immigrants in the Netherlands.

In the few studies in which the onset of attrition coincides with a total break in L1 use, i.e. studies dealing with adopted children, attrition is indeed very fast and, apparently definitive (Isurin, 2000; Nicoladis \& Grabois, 2002; Pallier et al., 2003; Ventureyra et al., this issue). 
These studies, however, concerned young children; for adults, there are numerous examples from studies which find evidence for attrition (or at least for L2 influence) despite the fact that the participants continue using their L1 on an often daily basis (e.g., Altenberg, 1991; Ben Rafael, 2001; Grosjean \& Py, 1991; Jarvis, 2003; Major, 1992; Olshtain \& Barzilay, 1991).

Thus, the role of the 'amount of contact' factor remains rather ambivalent. This might, at least in part, be ascribed to difficulties in the measurement of contact, as stressed by Köpke \& Schmid (2004). Researchers generally have to rely on self-reports which may in turn be influenced by language attitudes. Furthermore, it is not yet clear what role different kinds of language contact play. Should one focus on 'active' language use in the sense of output, or is regular input more important for language maintenance? With respect to L1 attrition in late bilinguals, I suggested above that a little contact might be enough to maintain a mature linguistic system and that input in the form of reading might be sufficient in many cases. While this issue had already been raised by Sharwood Smith \& Van Buren in 1991, it has been taken up only very recently by de Bot (2002). Sharwood Smith \& Van Buren's suggestion (1991: 23) was that external evidence is needed not only for developing a language system, but also for maintaining it. In the case of L1 attrition, the L1 would thus change "not because of lack of use but because of a lack of confirming evidence that the L1 is the way it is in a community of native speakers". Input would thus be determining as a source of confirming evidence. In the absence of sufficient L1 evidence due to lack of contact, the subject would rely on L2 input which would inevitably cause L2 interference (note that the neurological mechanisms underlying such processes are still unknown).

Furthermore, taking into consideration the input factor implies that not only quantity of input should be considered, but also quality. It has been suggested by several authors (Cook, 2003; de Bot et al., 1991; Köpke, 2001; Py, 1986) that attrition in subjects who are part of an immigrant community does not necessarily follow the same mechanisms as attrition in more isolated immigrants. As Cook (2003b: 14) puts it: "In addition, the problem is sometimes that the L2 user who is part of a minority in a culture may be socializing with a group of fellow L1 speakers. Over time these isolated L1 communities may evolve their own language." and further: "In these complex social situations, it is hard to decide whether there is really an effect of L2 on L1 or there has simply been an evolutionary change in the L1 as spoken by particular groups" (Cook, 2003b: 15).

In such cases, L1 input from other immigrants - already characterized by L2 influence ${ }^{\mathrm{xv}}-$ would gradually lead to the emergence of a new contact variety (cf. Grosjean \& Py, 1991). This is why it can be hypothesized that intensive contact with other immigrants in the host country is not necessarily the best condition for language maintenance, at least regarding native standards. It should be clear that such a modification of the linguistic norms in an immigrant group - as a sociolinguistic process - differs considerably from the erosion process taking place in individual immigrants that interests us here. One must, nevertheless, be aware of the existence of such phenomena.

What appears clearly in the literature is that attrition-and L2 influence more generally might occur at different levels, involving distinct mechanisms, as claimed by Sharwood Smith (1983b).

(a) First of all, with respect to chronology and frequency, as seen above, attrition may occur at the performance level, corresponding to stage 1 in Sharwood Smith's three stage framework.. Performance attrition can be ascribed to the competition between two linguistic systems in the on-line processing of languages, which results in higher activation thresholds and limitation of resources in the weaker language. Typical performance problems arise in lexical retrieval, but also include all kinds of errors due to processing difficulties, in time-constrained tasks in particular. These kinds of performance problems may - to a higher degree - also be found in pathological cases. Performance problems are best evidenced by research designs allowing the analysis of the role of task demands for L2 influence (e.g., Ammerlaan, 1996; Jarvis, 2003; Köpke, 1999; Major, 1992, etc.). Additionally, it is most likely that different tasks rely differently on linguistic knowledge: this is best illustrated by comparisons between judgment tasks and more informal oral production tasks which yield generally distinct results (for a detailed discussion of judgment tasks, see Altenberg \& Vago, 2004)

(b) Attrition may also entail a restructuring at the competence level (as in Sharwood Smith's stage 3): the case of the evolution of a language variety in linguistic minorities put aside, such 
restructuring has been mainly observed in children, but may also occur, to a lesser degree, in adults. If such restructuring can be ascribed to lack of L1 input as external evidence for the maintenance of L1, the mechanisms that govern the maintenance of a mature linguistic system need to be brought to light. It can be assumed that the question of input is different for children who are still in a developmental process. Nonetheless, the recent acknowledgement of L2 influence in late bilinguals and attrition phenomena in bilinguals and aging unilinguals suggest that such developmental processes may never end.

These distinct attrition levels are differently affected by L2 interference and evidently do not rely on the same mechanisms. This suggests a need for future studies focusing on the qualitative aspects of brain processing and on general cognition in the context of attrition. It should also be considered that different mechanisms may be operating simultaneously at different levels: namely environmental (input, linguistic norms, attitudes, etc.), psycholinguistic (interference, trace decline) and neurolinguistic (activation thresholds, resource attribution) factors. Conceivably, the interplay of several of these mechanisms is necessary to generate attrition.

\section{Conclusion and summary}

The questions which have been raised in this paper are fundamental for many research issues concerned with language processing in polyglots. The most important conclusion - to which the growing interest in attrition over the last twenty years has contributed substantially - is that language competence is not stable. A better understanding of language decline in healthy subjects - be it in the context of bilingualism or in normal aging - is crucially needed for a better assessment of language problems in pathological cases ${ }^{\mathrm{xvi}}$. The concept of a fluctuating linguistic multi-competence (Cook, 1992, 2003a; Grosjean, 1985, 1989) - which arises from taking into account the dynamics of language processing - thus seriously questions the mere existence of something like 'ultimate attainment' in language learning and perhaps the validity of other concepts concerning language processing.

The picture of attrition which can be drawn from the current findings shows that it is most likely that individual attrition is governed by processes which have their roots in the overall cognitive nature of memory. More and more converging evidence points towards L1 attrition in adults being essentially a psycho- or neurolinguistic issue related to brain and behavioral constraints. This conception of attrition is best illustrated by a recent definition given by de Bot (2002): "L1 language attrition is both a decline of retrievability of declarative linguistic knowledge and deproceduralization of linguistic knowledge in L1, and an increase of competition by L2 knowledge." This dimension of language attrition has so far not been acknowledged, despite its significance for a more comprehensive understanding of bilingualism in general. Accordingly, one of the most important conclusion that can be drawn after 20 years of attrition research is that-as outlined in Köpke \& Schmid (2004) - the most important extralinguistic factors shown to influence L1 attrition have their psycholinguistic counterparts:

- educational level (which, in some cases, seems to prevent attrition) can be linked to the amount of declarative knowledge of a language;

- the age effect in attrition is probably related to maturational constraints for language acquisition and growing automaticity (discussed in Goral, this issue);

- frequency of use has direct consequences on activation levels and thus influences the balance between the two languages.

Sociolinguistic studies brought the importance of these factors to light, but psycholinguistic and neurolinguistic research are urgently needed in order to explain why these factors are so important. This certainly is the most important research question to be challenged in the next years and the outcomes will be of interest for other scientific domains than attrition research alone. Complex research issues like bilingualism and attrition clearly require integrative approaches. As suggested by Albert, Tabor Connor \& Obler (2000), neurolinguistic and neuropsychological research would gain from taking into account environmental factors. Yet the reverse is also true, many professed sociolinguistic research domains might greatly benefit from being approached from a more biological angle. 
Comparisons between different populations and language situations have always been an important part of research (as the longevity of the Regression Hypothesis testifies). Such comparisons are essential as it is very unlikely that the general principles of human cognition change among populations.

The papers in the present issue are intended to be a first step in this direction. Each paper addresses the issues of the role of age and frequency of use-which have been the focus of this introduction - in a very different manner. Goral reviews the literature on healthy aging in unilinguals and on bilingual attrition with special attention to lexical retrieval. This approach is unique and complements the existing comparisons between language acquisition and attrition. Unlike bilingual attriters, aging subjects remain part of the L1 community and are not influenced by another language. The parallelisms between both types of processes not only illuminate some basic principles of language processing, but is also of paramount importance on account of the fact that many bilingual participants in attrition studies are aging persons. Gürel reports on L1 attrition of overt and null pronouns in Turkish immigrants with little contact with L1. It is one of the first papers where data from a linguistic study of L1 attrition are discussed with respect to a neuropsycholinguistic framework, in this case the Activation Threshold Hypothesis. This approach seems promising since the ATH appears to be valid for predicting what kind of linguistic structures will be more vulnerable to attrition. Ventureyra et al. present the first results of behavioral measures of phonetic perception in adopted Koreans. Other than in Goral's study, subjects under investigation here are characterized by a complete change in language use, having made a complete shift to L2. Since the adopted subjects were children at the onset of attrition, this study directly addresses the Critical Period Hypothesis. The findings underscore the results from a previous fMRI study with the same population (Pallier et al., 2003), which suggested that L1 had been completely forgotten by these subjects. Furthermore, the study suggests that phonetic aspects can be perfectly acquired past infancy, at least in such specific circumstances.

\section{Acknowledgements}

Many thanks go to Monika S. Schmid. Our continual work and discussions on attrition have greatly inspired this paper. I would further like to thank Jean-Luc Nespoulous and three anonymous reviewers for their helpful comments on an earlier draft of this paper.

\footnotetext{
${ }^{\mathrm{i}}$ It is not my intention here to challenge the holistic view of "the bilingual as a competent but specific speakerhearer" (Grosjean, 1985) or in the sense of Cook's multicompetence framework (Cook, 1992, 2003b) (see below).

ii Green's (1986) model is based on three key notions: control, activation, and resource. Concerning the first, Green claims that speech errors in healthy subjects but also most errors observed in aphasics are due to difficulties in controlling intact language systems. Control is obtained by the interplay of activation and inhibition mechanisms. With respect to activation, Green distinguishes 3 states. Accordingly, a language can be either selected (controlling linguistic processing), active (playing some role in linguistic processing though not being selected), or dormant (stored in long term memory without influencing ongoing linguistic processing). Finally, Green stresses that the control of the languages needs resources that are attributed to each language by a resource generator.

iii See, however, the data discussed by Green $(1998,2002)$ indicating that, in specific circumstances, reaction times might be longer in the dominant language.

iv The 'last-learned first-out' mechanism claimed by the Regression Hypothesis may also be linked to greater automaticity as suggested by Obler (1993: 189): "To the extent the Regression Hypothesis holds, we may argue that overlearned items are stored in some more automatic core which facilitates access."

${ }^{v}$ It has to be stressed that the onset of bilingualism and the onset of attrition are not necessarily the same, even if this is generally assumed. There might however be cases where a subject acquires two languages either simultaneously or successively and goes through a period of more or less balanced bilingualism due to external circumstances favoring the usage of both languages. Attrition would be expected in such a case only following a change in the subject's life which would considerably reduce the role of one of the languages.

${ }^{\mathrm{vi}}$ Note that similar findings have been reported for L2 or L3 attrition in children (Berman \& Olshtain, 1983; Kuhberg, 1992; Olshtain, 1986)

vii A model of second language acquisition/learning based on several hypotheses: the acquisition-learning hypothesis, monitor hypothesis, input hypothesis, natural order hypothesis, and affective filter hypothesis.
} 
viii This is illustrated by the fact that in the $\mathrm{CPH}$ literature (as well as in this paper) 'acquisition' and 'learning' are used interchangeably for both L1 and L2 most of the time.

${ }^{\text {ix }}$ L1 acquirers are young in general understanding, cognitively undeveloped, dispose of insufficient evidence and are not sensitive to correction or instruction. L2 learners are not so young, cognitively more developed, they dispose of very different (albeit still little) evidence and are generally sensitive to correction or instruction. Individual factors (intelligence, motivation, etc.) play a much greater role in L2 learning than in L1 acquisition, the latter showing much lesser variation in process and outcome (cf. Moskovsky, 2002).

$x$ "It is certainly conceivable that $[\ldots]$ early and late L2 acquirers process language differently, even if the resulting 'performance' is the same." (Obler, 1993: 185)

${ }^{x i}$ Or to a rising of its activation threshold that, eventually, makes the item inaccessible - as predicted by the Activation Threshold Hypothesis (Paradis, 1993, 2001).

${ }^{x i i}$ This is perhaps one of the reasons why the Contrastive Hypothesis (Lado, 1957) has not been more successful with respect to L2 learning.

xiii Note however that conceptual L2 interference has been observed for example by Pavlenko (2000) in RussianEnglish late bilinguals performing a film-telling task, suggesting that semantics may in other cases be one of the linguistic domains where L2 influence is most evident.

${ }^{x i v}$ Note that grammaticality judgments in English showed a similar influence from German. This may rather be a case of L2 influence in Cook's (2003a) understanding and not a case of attrition - all the more so since the subjects were a couple using L1 with each other on a daily basis.

${ }^{\mathrm{xv}}$ Many examples can be found in the ethnic minority papers in countries like the United States or Canada.

${ }^{x v i}$ The case of a hepta-lingual aphasic described by Galloway (1978) who can safely be assumed to have attrited in at least two of his seven languages, comes to mind.

\section{References}

Albert, M.L., Tabor Connor, L. \& Obler, L.K. (2000). Brain, language, and environment. Brain and Language, 71, 4-6.

Altenberg, E.P. (1991). Assessing first language vulnerability to attrition. In H.W. Seliger \& R.M. Vago (Eds.) First Language Attrition (pp. 189-206). Cambridge: Cambridge University Press.

Altenberg, E.P. \& Vago, R.M. (2004). The role of grammaticality judgments in investigating first language attrition: a cross-disciplinary perspective. In M.S. Schmid, B. Köpke, M. Keijser \& L. Weilemar (Eds.) First Language Attrition: Interdisciplinary Perspectives on Methodological Issues (pp. 105-129). Amsterdam: John Benjamins.

Ammerlaan, T. (1996). 'You get a bit wobbly...' - Exploring bilingual lexical retrieval processes in the context of first language attrition. Unpublished Doctoral Dissertation. Nijmegen: Katholieke Universiteit.

Archibald, J. \& Libben, G. (1995). Research Perspectives on Second Language Acquisition. Toronto: Copp Clark.

Ben Rafael, M. (2001). Contact de langues: le français parlé des francophones israéliens. Unpublished Doctoral Dissertation. University of Tel Aviv.

Berman, R.A. \& Olshtain, E. (1983). Features of first language transfer in second language attrition. Applied Linguistics, 4 (3), 222-234.

Birdsong, D. (1999). Second Language Acquisition and the Critical Period Hypothesis. Mahwah, NJ: Lawrence Erlbaum Associates.

Birdsong, D. \& Molis, M. (2001). On the evidence of maturational constraints in secondlanguage acquisition. Journal of Memory and Language, 44, 235-249.

Bley-Vroman, R. (1989). What is the logical problem of foreign language learning? In S. Gass \& J. Schachter (Eds.) Linguistic Perspectives on Second Language Acquisition (pp. 41-68). New York: Cambridge University Press.

Bloomfield, L. (1933). Language. New York: Holt.

Bode, S. de (1996). First language attrition: Productive morphology disintegration and neurobiological support. Unpublished MA Thesis. Pomona: California State Polytechnic University.

Bolonyai, A. (1999). The hidden dimension of language contact: The case of HungarianEnglish bilingual children. Unpublished Doctoral Dissertation. Columbia, SC: University of South Carolina. 
Bot, K. de (2001). Language use as an interface between sociolinguistic and psycholinguistic processes in language attrition and language shift. In J. Klatter-Folmer \& P. van Avermaet (Eds.) Theories on maintenance and loss of minority languages. Towards an more integrated explanatory framework (pp. 65-82). Münster: Waxmann.

Bot, K. de (2002, August). Language attrition - where are we and where are we going? Paper presented at the International Conference on First Language Attrition, Amsterdam. (see http://www.let.vu.nl/events/2002/langatt.nsf/extern/home)

Bot, K. de \& Clyne, M. (1994). A 16-year longitudinal study of language attrition in Dutch immigrants in Australia. Journal of Multilingual and Multicultural Development, 15 (1), 17-28.

Bot, K. de, Gommans, P. \& Rossing, C. (1991). L1 loss in an L2 environment: Dutch immigrants in France. In H.W. Seliger \& R.M. Vago (Eds.) First Language Attrition (pp. 87-98). Cambridge: Cambridge University Press.

Bot, K. de \& Weltens, B. (1991). Recapitulation, regression, and language loss. In H.W. Seliger \& R.M. Vago (Eds.) First Language Attrition (pp. 31-52). Cambridge: Cambridge University Press.

Bouba, M., Filiaci, F., Heycock, C., Sorace, A. \& Tsimpli, I. (2002, August). Syntactic attrition in Greek and Italian near-native speakers of English. Paper presented at the International Conference on First Language Attrition, Amsterdam.

Caramazza, A. \& Zurif, E.B. (1978). Language Acquisition and Language Breakdown. Baltimore: John Hopkins University Press.

Christian, C.C. (1977). Minority language skills before age three. In W.F. Mackey \& T. Andersson (Eds.) Bilingualism in Early Childhood (pp. 94-108). Rowley, MA: Newbury House.

Clyne, M. (1986). Towards a systematization of language contact dynamics. In J. Fishman, A. Tabouret-Keller, M. Clyne, Bh. Krishnamurti \& M. Abdulaziz (Eds.) The Fergusian Impact: In Honor of Charles A. Ferguson on the Occasion of his 65th Birthday. Vol. II Sociolinguistics and the Sociology of Language (pp. 483-492). Berlin: Mouton de Gruyter.

Clyne, M. (2001). Paradigm hopping and other feats from Veldhoven. In J. Klatter-Folmer \& P. van Avermaet (Eds.) Theories on maintenance and loss of minority languages. Towards an more integrated explanatory framework (pp. 141-151). Münster: Waxmann.

Cook, V. (1992). Evidence for multicompetence. Language Learning, 42, 557-591.

Cook, V. (2003a). Effects of the Second Language on the First. Clevedon: Multilingual Matters.

Cook, V. (2003b). Introduction: The changing L1 in the L2 user's mind. In V. Cook (Ed.) Effects of the Second Language on the First (pp 1-18). Clevedon: Multilingual Matters.

Curtiss, S. (1977). Genie: A psycholinguistic study of a modern day wild child. New York: Academic Press.

Cuza, A. (2002). Attrition and the 'compounding parameter': L1 Spanish in a contact situation with English. International Conference on First Language Attrition: Interdisciplinary Perspectives on Methodological Issues. Amsterdam: Vrije Universiteit.

Damasio, A.R., Castro-Caldas, A., Grosso, J.T. \& Ferro, J.M. (1976). Brain specialization for language does not depend on literacy. Archives of Neurology, 33, 300-301.

De Agostini, M. (2002). Spécialisation hémisphérique chez l'enfant. Revue de Neuropsychologie, 12 (1), 165-184.

De Bruijn, E.R.A., Dijkstra, T., Chwilla, D.J. \& Schriefers, H.J. (2001). Language context effects on interlingual homograph recognition: evidence from event-related potentials and response times in semantic priming. Bilingualism: Language and Cognition, 4 (2), $155-$ 168.

DeKeyser, R.M. (2000). The robustness of critical period effects in second language acquisition. Studies in Second Language Acquisition, 22, 499-533.

Dewaele, J.-M. (2004). Perceived language dominance and language preference for emotional speech : The implications for attrition research. In M.S. Schmid, B. Köpke, M. Keijser \& L. Weilemar (Eds.) First Language Attrition: Interdisciplinary Perspectives on Methodological Issues (pp. 81-104). Amsterdam: John Benjamins.

Ebbinghaus, H. (1885). Über das Gedächtnis. Untersuchungen zur experimentellen Psychologie. Leipzig: Duncker \& Humblot. 
Frenck-Mestre, C. (1993). Use of orthographic redundancies and word identification speed in bilinguals. Journal of Psycholinguistic Research, 22 (4), 397-410.

Fujita, M. (2002). Second language English attrition of Japanese bilingual children. Dissertation Abstracts International, Section A: The Humanities and Social Sciences (DAIA), 63(1), 59-60.

Galloway, L.M. (1978). Language impairment and recovery in polyglot aphasia: A case study of a hepta-lingual. In M. Paradis (Ed.) Aspects of Bilingualism (pp. 139-147). Columbia, SC: Hornbeam Press.

Gardner, R.C. (1982). Social factors in language retention. In R.D. Lambert \& B.F. Freed (Eds.) The Loss of Language Skills (pp. 24-43). Rowley: Newbury House.

Gardner, R.C. \& Lambert, W.E. (1972). Attitudes and motivation in second language learning. Rowley: Newbury House.

Goebl, H., Nelde, P.H., Stary, Z. \& Wölck, W. (1996). Contact Linguistics. New York: De Gruyter.

Goral, M., Levy, E.S., \& Obler, L.K. (2002). Neurolinguistic aspects of bilingualism. The International Journal of Bilingualism, 6 (4), 411-440.

Green, D.W. (1986). Control, activation and resource: A framework and a model for the control of speech in bilinguals. Brain and Language, 27, 210-223.

Green, D.W. (1998). Mental control of the bilingual lexico-semantic system. Bilingualism: Language and Cognition, 1, 67-81.

Green, D.W. (2002). Representation and control: Exploring recovery patterns in bilingual aphasics. In F. Fabbro (Ed.) Advances in the Neurolinguistics of Bilingualism. Essays in Honor of Michel Paradis (pp.239-260). Undine: Forum.

Grimshaw, G.M., Adelstein, A., Bryden, M.P \& MacKinnon, G.E. (1998). First-languageacquisition in adolescence: Evidence for a critical period of verbal language development. Brain and Language, 63 (2), 237-255.

Grosjean, F. (1985). The bilingual as a competent but specific speaker-hearer. Journal of Multilingual and Multicultural Development, 6, 467-477.

Grosjean, F. (1989). Neurolinguists, beware! The bilingual is not two monolinguals in one person. Brain and Language, 36, 3-15.

Grosjean, F. \& Py, B. (1991). La restructuration d'une première langue: l'intégration de variants de contact dans la competence de migrants bilingues. La Linguistique, 27, 35-60.

Gross, S. (2000). The role of abstract lexical structure in first language attrition: Germans in America. Unpublished Doctoral Dissertation. Columbia SC: University of South Carolina.

Gürel, A. (2002). Linguistic characteristics of second language acquisition and first language attrition. Turkish overt versus null pronouns. Unpublished Doctoral Dissertation. Montreal: McGill University.

Hahne, A. \& Friederici, A.D. (2001). Processing a second language: late learners' comprehension mechanisms as revealed by event-related brain potentials. Bilingualism: Language and Cognition, 4 (2), 123-142.

Hakuta, K., Bialystok, E. \& Wiley, E. (2003). Critical evidence: A test of the critical period hypothesis for second language acquisition. Psychological Science, 14 (1), 31-38.

Harley, B. \& Wang, W. (1997). The critical period hypothesis: Where are we now? In A.M.N. de Groot \& J.F. Kroll (Eds.), Tutorials in Bilingualism. Psycholinguistic Perspectives (pp. 19-52). Mahwah, NJ: Lawrence Erlbaum Associates.

Hulsen, M. (2000). Language loss and language processing. Three generations of Dutch migrants in New Zealand. Unpublished Doctoral Dissertation. Nijmegen: Katholieke Universiteit.

Hutz, M. (2004). Is there a natural process of decay? A longitudinal study of language attrition. In M.S. Schmid, B. Köpke, M. Keijser \& L. Weilemar (Eds.) First Language Attrition: Interdisciplinary Perspectives on Methodological Issues (pp. 189-206). Amsterdam: John Benjamins.

Hyltenstam, K. \& Obler, L.K. (1989). Bilingualism across the lifespan: Aspects of acquisition, maturity, and loss. Cambridge: Cambridge University Press.

Isurin, L. (2000). Deserted islands or a child's first language forgetting. Bilingualism: Language and Cognition, 3, 151-166. 
Jakobson, R. (1941). Kindersprache, Aphasie und allgemeine Lautgesetze. Uppsala: Almqvist \& Wiksell.

Jarvis, S. (2003). Probing the effects of the L2 on the L1: A case study. In Cook, V. (Ed.) Effects of the Second Language on the First (pp. 81-102). Clevedon: Multilingual Matters.

Jaspaert, K. \& Kroon, S. (1989). Social determinants of language loss. Review of Applied Linguistics (I.T.L.), 83/84, 75-98.

Jaspaert, K. \& Kroon, S. (1992). From the typewriter of A.L.: A case study of language loss. In W. Fase, K. Jaspaert \& S. Kroon (Eds.) Maintenance and Loss of Minority Languages (pp. 137-147). Amsterdam: John Benjamins.

Jordens, P., de Bot, K., van Os, C. \& Schumans, J. (1986). Regression in German case marking. In B. Weltens, K. de Bot \& T. van Els (Eds.) Language Attrition in Progress (pp. 159-176). Dordrecht: Foris.

Jordens, P., de Bot, K. \& Trapman, H. (1989). Linguistic aspects of regression in German case marking. Studies of Second Language Acquisition, 11, 179-204.

Kaufman, D. (2001). Tales of L1 attrition - Evidence from pre-puberty children. In T. Ammerlaan, M. Hulsen, H. Strating \& K. Yagmur (Eds.) Sociolinguistic and Psycholinguistic Perspectives on Maintenance and Loss of Minority Languages (pp. 185202). Münster: Waxmann.

Kaufman, D. \& Aronoff, M. (1991). Morphological disintegration and reconstruction in first language attrition. In H.W. Seliger \& R.M. Vago (Eds.) First Language Attrition (pp. 175188). Cambridge: Cambridge University Press.

Kilborn, K. (1989). Sentence processing in a second language: The time of transfer. Language and Speech, 32 (1), 1-23.

Kim, K.H.S., Relkin, N.R., Lee, K.-M. \& Hirsch, J. (1997). Distinct cortical areas associated with native and second languages. Nature, 388, 171-174.

Klein, D., Zatorre, R.J., Milner, B., Meyer, E. \& Evans, A.C. (1995). The neural substrates of bilingual language processing: Evidence from positron emission tomography. In M.Paradis (Ed.) Aspects of Bilingual Aphasia (pp. 23-36). Oxford: Pergamon Press.

Köpke, B. (1999). L'attrition de la première langue chez le bilingue tardif: implications pour l'étude psycholinguistique du bilinguisme. Unpublished Doctoral Dissertation. Toulouse: Université de Toulouse-Le Mirail.

Köpke, B. (2000). Effet du pays d'accueil sur le maintien de la langue. Le cas des immigrés d'origine allemande. Education et Sociétés Plurilingues / Educazione e Societa' Plurilingue, 9, 59-65.

Köpke, B. (2001). Quels changements linguistiques dans l'attrition de la L1 chez le bilingue tardif? TRANEL, 34/35, 355-368.

Köpke, B. (2002). Activation thresholds and non-pathological first language attrition. In F. Fabbro (Ed.) Advances in the Neurolinguistics of Bilingualism Essays in Honor of Michel Paradis (pp.119-142). Undine: Forum.

Köpke, B. \& Schmid, M.S. (2004). Language attrition: the next phase. In M.S. Schmid, B. Köpke, M. Keijser \& L. Weilemar (Eds.) First Language Attrition: Interdisciplinary Perspectives on Methodological Issues (pp. 1-43). Amsterdam: John Benjamins.

Krashen, S. (1981). Second Language Acquisition and Second Language Learning. New York: Pergamon Press.

Kuhberg, H. (1992). Longitudinal L2-attrition versus L2-acquisition, in three Turkish children - empirical findings. Second Language Research, 8, 138-153.

Lachman, R. \& Mistler-Lachman, J. (1976). Dominance lexicale chez le bilingue. Bulletin de Psychologie, 15, 281-288.

Lado, R. (1957). Linguistics across cultures: Applied linguistics for language teachers. Ann Arbor: University of Michigan Press.

Laufer, B. (2003). The influence of L2 on L1 collocational knowledge and on L1 lexical diversity in free written expression. In V. Cook (Ed.) Effects of the Second Language on the First (pp. 19-31). Clevedon: Multilingual Matters.

Lecours, A.R., Mehler, J., Parente, M.A., Caldeira, A., Cary, L., Castro, M.J., Dehaut, F., Delgado, R., Gurd, J., De Fraga Karmann, D., Jakubovitz, R., Osorio, Z., Scliar Cabral, L. \& Soares Junqueira, A.M. (1987). Illiteracy and brain damage - 1. Aphasia testing in culturally contrasted populations (control subjects). Neuropsychologia, 25, 231-245. 
Lecours, A.R., Mehler, J. \& Parente, M.A., Beltrami, M.C., Canossa de Tolipan, L. Cary, L., Castro, M.J., Carrono, V., Chagastelles, L., Dehaut, F., Delgado, R., Evangelista, A. et al. (1988). Illiteracy and brain damage - 3. A contribution to the study of speech and language disorders in illiterates with unilateral brain damage (initial testing). Neuropsychologia, 26, 575-589.

Lenneberg, E.H. (1967). Biological Foundations of Language. New York: Wiley.

Loftus, E.F. (1980). Memory: Surprising new insights into how we remember and why we forget. Reading, MA: Addison-Wesley Publishing Co.

Long, M.H. (1993). Second language acquisition as a function of age: Research findings and methodological issues. In K. Hyltenstam \& A. Viberg (Eds.) Progression and regression in language (pp. 196-221). Cambridge: Cambridge University Press.

Mack, M.A. (1983). Psycholinguistic consequences of early bilingualism: A comparative study of the performance of English monolinguals and French-English bilinguals in phonetics, syntax, and semantic experiments. Unpublished Doctoral Dissertation. Rhode Island: Brown University.

Mack, M.A. (2002). The influence of neuroscience upon linguistics from a historical perspective. In F. Fabbro (Ed.) Advances in the Neurolinguistics of Bilingualism. Essays in Honor of Michel Paradis (pp. 143-192). Undine: Forum.

Mägiste, E. (1979). The competing language systems of the multilingual: A developmental study of decoding and encoding processes. Journal of Verbal Learning and Verbal Behavior, 18, 79-89.

Mägiste, E. (1985). Development of intra- and interlingual interference in bilinguals. Journal of Psycholinguistic Research, 14 (2), 137-154.

Major, R.C. (1992). Losing English as a first language. The Modern Language Journal, 76 (2), 190-208.

McCormack, B. (2001). The maintenance and loss of reflexive anaphors in L2 English. Unpublished Doctoral Dissertation. University of Durham.

Métellus, J., Cathala, H.P., Issartier, A. \& Bodak, A. (1981). Une étude d'aphasie chez une illetrée (analphabète): réflexions critiques sur les fonctions cérébrales concourant au langage. Annales Médico-Psychologiques, 139, 992-1001.

Minkowski, M. (1928). Sur un cas d'aphasie chez un polyglotte. Revue Neurologique, 49, 361-366.

Montrul, S. (2002). Incomplete acquisition and attrition of Spanish tense/aspect distinctions in adult bilinguals. Bilingualism: Language and Cognition, 5, 39-68.

Moorcroft, R. \& Gardner, R.C. (1987). Linguistic factors in second language loss. Language Learning, 37 (3), 327-340.

Moskovsky, C. (2002). The critical period hypothesis revisited. In C. Allen (Ed.) The 2002 Proceedings of the 2001 Conference of the Australian Linguistic Society. http://www.linguistics.anu.edu.au/ALS2001/papers/Moskovsky.pdf

Myers-Scotton, C. (2002). Contact Linguistics. Bilingual Encounters and Grammatical Outcomes. New York: Oxford University Press.

Myers-Scotton, C. \& Jake, J. (2000). Four types of morphemes: Evidence from aphasia, codeswitching, and second language acquisition. Linguistics, 8 (6), 1053-1100.

Nicoladis, E. \& Grabois, H. (2002). Learning English and losing Chinese: A case study of a child adopted from China. International Journal of Bilingualism, 6 (4), 441-454.

Nilsson, L.-G. \& Baeckman, L. (1989). Implicit memory and the enactment of verbal instruction. In S. Lewandowsky, J. Dunn \& K. Kirsner (Eds.) Implicit Memory: Theoretical issues. Hillsdale, NJ: Lawrence Erlbaum Associates.

Obler, L.K. (1982). Neurolinguistic aspects of language loss as they pertain to second language attrition. In R.D. Lambert \& B.F. Freed (Eds.) The Loss of Language Skills (pp. 60-79). Rowley, MA: Newbury House.

Obler, L.K. (1993). Neurolinguistic aspects of second language development and attrition. In K.Hylstenstam \& A.Viberg (Eds.) Progression and Regression in Language (pp. 178-195). Cambridge: Cambridge University Press.

Obler, L.K. \& Mahecha, N.R. (1991). First language loss in bilingual and polyglot aphasics. In H.W. Seliger \& R.M. Vago (Eds.) First Language Attrition (pp. 53-66). Cambridge: Cambridge University Press. 
Olshtain, E. (1986). The attrition of English as a second language with speakers of Hebrew. In B. Weltens, K. de Bot \& T. van Els (Eds.) Language Attrition in Progress (pp. 185-204). Dordrecht: Foris.

Olshtain, E. (1989). Is second language attrition the reversal of second language acquisition? Studies in Second Language Acquisition, 11 (2), 151-165.

Olshtain, E. \& Barzilay, M. (1991). Lexical retrieval difficulties in adult language attrition. In H.W. Seliger \& R.M. Vago (Eds.) First Language Attrition (pp. 139-150). Cambridge: Cambridge University Press.

Ó Laoire, M. (2002, October). An overview of bilingualism and immersion education in Ireland: Complexity and change. Paper presented at the Second International Symposium on Bilingualism. Bilingualism and education, from the family to the school, Vigo, Spain.

Pallier, C., Dehaene, S., Poline, J.-B., LeBihan, D., Argenti, A.-M., Dupoux, E. \& Mehler, J. (2003). Brain imaging of language plasticity in adopted adults: Can a second language replace the first? Cerebral Cortex, 13, 155-161.

Pan, B. \& Gleason, J. (1986). The study of language loss: Models and hypotheses for an emerging discipline. Applied Psycholinguistics, 7, 193-206.

Paradis, M. (1980). The language switch in bilinguals: Psycholinguistic and neurolinguistic perspectives. In P.H. Nelde (Ed.) Sprachkontakt und Sprachkonflikt (pp. 501-506). Wiesbaden: Franz Steiner.

Paradis, M. (1993). Linguistic, psycholinguistic, and neurolinguistic aspects of 'interference' in bilingual speakers: The Activation Threshold Hypothesis. International Journal of Psycholinguistics, 9 (2), 133-145.

Paradis, M. (1994). Neurolinguistic aspects of implicit and explicit memory: Implications for bilingualism and SLA. In N. Ellis (Ed.) Implicit and explicit learning of languages (pp. 393-419). London: Academic Press.

Paradis, M. (2001). An integrated neurolinguistic theory of bilingualism (1976-2000). LACUS Forum 27, 5-15.

Paradis, M. (2003). The bilingual Loch Ness Monster raises its non-asymmetric head againor, why bother with such cumbersome notions as validity and reliability? Comments on Evans et al. (2002). Brain and Language, 87, 441-448.

Pavlenko, A. (2000). L2 influence on L1 in late bilingualism. Issues in Applied Linguistics, $11(2), 175-205$.

Pavlenko, A. (2002a). Bilingualism and emotions. Multilingua, 21 (1), 45-78.

Pavlenko, A. (2002b). Conceptual change in bilingual memory: A Neo Whorfian approach. In F. Fabbro (Ed.) Advances in the Neurolinguistics of Bilingualism. Essays in Honor of Michel Paradis (pp. 69-94). Undine: Forum.

Pavlenko, A. (2003). 'I feel clumsy speaking Russian': L2 influence on L1 in narratives of Russian L2 users of English. In V. Cook (Ed.) Effects of the Second Language on the First (pp. 32-61). Clevedon: Multilingual Matters.

Pelc, L. (2001). L1 lexical, morphological and morphosyntactic attrition in Greek-English bilinguals. Unpublished Doctoral Dissertation. New York: CUNY.

Penfield, W. \& Roberts, L. (1959). Speech and Brain Mechanisms. Princeton NJ: Princeton University Press.

Perani, D., Dehaene, S., Grassi, F., Cohen, L., Cappa, S.F., Dupoux, E., Fazio, F. \& Mehler, J. (1996). Brain processing of native and foreign languages.Neuroreport, 7, 2439-2444.

Platzack, C. (1998). The initial hypothesis of syntax: a minimalist perspective on language acquisition and attrition. In $\mathrm{H}$. Clahsen (Ed.) Generative Perspectives on Language Acquisition (pp. 369-414). Amsterdam: John Benjamins.

Py, B. (1986). Native language attrition amongst migrant workers: Towards an extension of the concept of interlanguage. In E. Kellermann \& M. Sharwood Smith (Eds.) Crosslinguistic Influence in Second Language Acquisition (pp. 163-172). New York: Pergamon Press.

Schacter, D. (1985). Implicit and explicit memory for new associations in normal and amnesic subjects. Journal of Experimental Psychology: Learning, Memory, and Cognition, 11, 501518.

Schmid, M.S. (2002). First language attrition, use, and maintenance. The case of German Jews in Anglophone countries. Amsterdam: John Benjamins. 
Schmid, M.S. (2004). Identity and attrition: a historical approach. To appear in: A. Pavlenko \& J.M. Dewaele (Eds.) Bilingualism and Emotions. Special issue of Estudios de Sociolinguistica, 5 (1) 41-58.

Schmitt, E. (2001). Beneath the surface: signs of language attrition in immigrant children from Russia. Unpublished Doctoral Dissertation. University of South California.

Schoenmakers-Klein Gunnewiek, M. (1998). Taalverlies door taalcontact? Een onderzoek bij Portugese migranten. Tilburg: Tilburg University Press.

Schumann, J. (1998). The neurobiology of affect in language. (Language Learning Monograph Series) University of Michigan: Blackwell Publishers.

Segalowitz, N. (1991). Does advanced skill in a second language reduce automaticity in the first language? Language Learning, 4, 59-83.

Seliger, H.W. (1989). Deterioration and creativity in childhood bilingualism. In K. Hylstenstam \& L.K. Obler (Eds.) Bilingualism Across the Lifespan (pp. 173-184). Cambridge: Cambridge University Press.

Seliger, H.W. (1991). Language attrition, reduced redundancy, and creativity. In H.W. Seliger \& R.M. Vago (Eds.) First Language Attrition (pp. 227-240). Cambridge: Cambridge University Press.

Seliger, H.W. \& Vago, R.M. (1991). First Language Attrition. Cambridge: Cambridge University Press.

Selinker, L. (1969). Language transfer. General Linguistics, 9, 67-92.

Sharwood Smith, M.A. (1983a). On first language loss in the second language acquirer: Problems of transfer. In S.Gass \& L.Selinker (Eds.) Language transfer in language learning (pp. 222-231). Rowley, MA: Newbury House.

Sharwood Smith, M.A. (1983b). On explaining language loss. In R. Felix \& H. Wode (Eds.) Language Development at the Crossroads (pp. 49-59). Tübingen: Gunter Narr Verlag.

Sharwood Smith, M.A. (1989). Crosslinguistic influence in language loss. In K. Hyltenstam \& L.K. Obler (Eds.) Bilingualism across the lifespan (pp. 185-201). Cambridge: Cambridge University Press.

Sharwood Smith, M.A. \& Van Buren, P. (1991). First language attrition and the parameter setting model. In H.W. Seliger \& R.M. Vago (Eds.) First Language Attrition (pp. 17-30). Cambridge: Cambridge University Press.

Soares, C. \& Grosjean, F. (1984). Bilinguals in a monolingual and a bilingual speech mode: The effect on lexical access. Memory and Cognition, 12 (4), 380-386.

Sorace, A. (2000). Differential effects of attrition in the L1-syntax of near-native L2 speakers. In C. Howell, S. Fish \& T. Keith-Lucas (Eds.) Proceedings of the $24^{\text {th }}$ Boston University Conference on Language Development (pp. 719-725). Somerville, MA: Cascadilla Press.

Thiery, C. (1976). Le bilinguisme vrai. Etudes de Linguistique Appliquée, 24, 52-63.

Turian, D. \& Altenberg, E.P. (1991). Compensatory strategies of child first language attrition. In H.W. Seliger \& R.M. Vago (Eds.) First Language Attrition (pp. 207-226). Cambridge: Cambridge University Press.

Ullman, M.T. (2001). The neural basis of lexicon and grammar in first and second language: the declarative/procedural model. Bilingualism: Language and Cognition, 4 (1), 105-122.

Underwood, B.J. (1957). Interference and forgetting. Psychological Review, 64, 49-60.

Vago, R.M. (1991). Paradigmatic regularity in first language attrition. In H.W. Seliger \& R.M. Vago (Eds.) First Language Attrition (pp. 241-252). Cambridge: Cambridge University Press.

Weber-Fox, C.M. \& Neville, H.J. (1996). Maturational constraints on functional specializations for language processing: ERP and behavioral evidence in bilingual speakers. Journal of Cognitive Neuroscience, 8 (3), 231-256.

Wechsler, A.F. (1976). Crossed aphasia in an illiterate dextral. Brain and Language, 3, 164172.

Weinreich, U. (1953). Languages in contact: Findings and problems. New York: Linguistic Circle of New York.

Yagmur, K. (1997). First Language Attrition Among Turkish Speakers in Sydney. Tilburg: Tilburg University Press.

Yoshida, R. (2002, October). Multilingual children's negotiations of literacy practices in home and school contexts: Seven case studies of the Heritage Language Research Group. 
Paper presented at the Second International Symposium on Bilingualism. Bilingualism and education, from the family to the school, Vigo, Spain.

Yoshitomi, A. (1992). Towards a model of language attrition: Neurobiological and psychological contributions. Issues in Applied Linguistics, 3 (2), 293-318.

Zobl, H. (1995). Converging evidence for the 'acquisition-learning' distinction. Applied Linguistics, 16 (1), 35-56.

Barbara Köpke

Laboratoire Jacques Lordat

Université de Toulouse-Le Mirail

5 allées A. Machado

31058 Toulouse Cedex

France

bkopke@univ-tlse2.fr 